pp. $478-488$

\title{
How Artificial Intelligence Changes the Future of Accounting Industry
}

Submitted 25/04/20, $1^{\text {st }}$ revision 28/05/20, $2^{\text {nd }}$ revision 09/06/20, accepted 30/07/20

Suleiman Jamal Mohammad ${ }^{1}$, Amneh Khamees Hamad ${ }^{2}$, Hela Borgi ${ }^{3}$, Phung Anh Thu ${ }^{4}$, Muhammad Safdar Sial ${ }^{5}$, Ali Abdallah Alhadidi ${ }^{6}$

\section{Abstract:}

Purpose: The main theme of the study relates to the assessment of the impact of artificial intelligence on accounting professionals, especially the upcoming generation of an accountant. The study aims to assess the effects of the introduction of AI-based systems in the field of accounting and answer the question of how it has changed the world of accounting professionals and to forward relevant suggestions to policymakers.

Design/Approach/Methodology: The study consists of the results of qualitative document analysis on the topic of artificial intelligence in the accounting industry.

Findings: The research concludes that the serious concerns amongst the practicing accountant in the present-day world can be replaced by an Artificial Intelligence-based automated system. To avoid this fate, the accountants need not only to adapt to the use of information technology but also need to adapt to the ever-changing business environment.

Practical Implication: It has been recommended that to enhance the performance and effectiveness of accounting functions the accountants and accounting firms should keep abreast of continuous improvements in artificial intelligence in their field, which will eventually lead to a reduction in accounting costs to the firm along with adding value to the accounting industry by shifting the focus of accountants to data-driven and analytics-based decision from existing monotonous tasks.

Originality/Value: The study is original and it adds to scholarly debate on how the technology revolution changes the future of the accounting industry.

Keywords: Artificial Intelligence, accounting, transformation.

JEL Classification: M41, M42.

Paper Type: Research Article. ISNN: 2241-4754, H index 10, Q3.

Acknowledgement: This research was funded by the Deanship of Scientific Research at Princess Nourah bint Abdulrahman University through the Fast-track Research Funding Program.

\footnotetext{
${ }^{1}$ Princess Sumaya University for Technology, Department of Accounting, Amman, Jordan, e-mail:s.mohmmad@psut.edu.jo

${ }^{2}$ University of Jordan, Department of Accounting, Amman, Jordan, e-mail:

a.hamad@ju.edu.jo

${ }^{3}$ Accounting department/ Colleage of Business and Administration, Princess Nourah bint Abdulrahman University Saudi Arabia,e-mail: haborgi@pnu.edu.sa

${ }^{4}$ Corresponding author, Faculty of Finance and Accounting, Nguyen Tat Thanh University,

Ho Chi Minh City 700000, Vietnam, e-email: pathu@ntt.edu.vn

${ }^{5}$ Department of Management Sciences, COMSATS University Islamabad, Pakistan,

e-mail:safdar.sial786@gmail.com

${ }^{6}$ Jordan Airports Company, Amman, Jordan, e-mail: ahadidi@jac.jo
} 


\section{Introduction}

With the introduction and continuous improvements in computer systems, the accounting information system has evolved into much more than just paper-based ledgers and journals, but at the same time, many instances show that the computer systems were used more likely as an efficient type of paper or just a calculator, hence resulting in the development of vast databases of limited accounting information related to certain accounting transactions for the benefit of the company. Such databases do not facilitate the decision-makers in any way. One of the possible solutions to such a problem is to introduce Artificial Intelligence (AI) within the computer system of the company, with emphasis on developing such a system that would be able to work and react like humans and do tasks like problem-solving, planning, learning and speech recognition. Such a system would be able to overcome the problems and difficulties with the traditional accounting information system. There have been numerous studies on accounting information systems and databases, but extremely limited work is seen on Artificial Intelligence applications in accounting.

Operations of financial institutions have rapidly changed with the introduction of Artificial Intelligence due to cost-saving and operational efficiency; AI is expected to soon take over the core functions of financial institutions as well (Dilek, Çakır, and Aydin, 2015). Due to drastic demand and application of AI, significant improvements have been made especially concerning accounting which has led to the transformation of paper-based accounting entries to software and computer entries. Artificial Intelligence has a long history concerning the accounting profession. It has been applied in the field of accounting and auditing for more than 25 years now (Greenman, 2017). Yudkowsky (2008) concluded that people thinking that they understand it very quickly is one of the biggest dangers of Artificial Intelligence.

Nowadays, Artificial Intelligence is being incorporated in almost all aspects of accounting spawning fear and nervousness in accounting professionals regarding human involvement in a company's accounting and finance affairs shortly. A study by the University of Oxford in 2015 shows that there is a 95 percent probability that the accountants will lose their jobs due to machines taking over their tasks (Griffin, 2016). At the same time, Greenman (2017) also stated that the same report also forecasted addition of new jobs in the market along with the elimination of others, which means that Artificial Intelligence, will make the accounting profession more efficient and effective by removing the painstaking and tedious tasks it its absence.

The world of finance and accounting can be greatly benefited by the introduction of AI tools and techniques enabling automation of tasks leading to improvement in analysis capability as compared to previous techniques that are quickly being outdated. Even though AI brings in a lot of good chances, it also has certain 
limitations that may be unsuitable to perform certain activities. There is a wide range of risks that are also associated with adequate management of AI in an organization. The main aim of this paper is to study and explore how different industries have employed AI, specifically in finance.

\section{Literature Review and Research Questions}

The study addresses the following research questions: What is the evolution of Artificial Intelligence? How is Artificial Intelligence adopted globally and in China? What are the potential opportunities for the application of Artificial Intelligence? What are the potential threats of the application of Artificial Intelligence in the Field of Accounting? How to improve the application of Artificial Intelligence? How does the future of AI look like?

\subsection{Evolution of Artificial Intelligence}

The development of AI has continuously challenged the limits of human creation and has progressed quickly since the previous century. "El Ajedrecsta", first computer game invented in 1914 by Spanish named Leonardo Tores y Quevedo automatically played chess through an algorithm embedded into the machine hardware (A Timeline of AI, 2016). It was observed that researchers from different fields were collaborating to work out and brainstorms the future of AI. Most prominently John McCarthy, Marvin Minsky, Nathaniel Rochester, and Claude Shannon from Dartmouth College, proposed a research project on the future of artificial intelligence. The main objective of the project was "to find out how to make machine use language, form abstractions and concepts, solve kinds of problems now reserved for humans, and improve themselves" (McCarthy, Minsky, Rochester, Shannon, 2006). This summer research project inspired many other researchers from diverse backgrounds and further highlighted the overwhelming importance of artificial intelligence.

Shortly afterward, in 1966 ELIZA the world's first chat program was developed by Joseph Weizenbaum which communicated with the users using programmed phrases. Further in 2000, a robot named "Kismet" was developed by Cynthia Breazeal that analyzed social cues and expressions to interact with humans. Highly publicized IBM's Watson was among the finest achievements in Artificial Intelligence. In 2011, Watson proved its exceptional intelligence in a three-night competition on Jeopardy. The idea was to put Watson against Jeopardy's longest and most successful winners, Ken Jennings and Brad Rutter. IBM researchers put in a great effort to ensure Watson would dominate the contest, resulted in the development of "DeepOA" software which could query 200 million pages of information (Best, 2017). Watson easily defeated both of the most successful Jeopardy contestants and this led to new ideas and previously unexplored and exciting questions for the IBM team. Watson's development team then shifted its focus in the healthcare services industry and used Watson with Memorial Sloan- 
Kettering Cancer Center and WellPoint Insurance (Best). Watson was used in patient diagnosis along with various treatment and therapy methods. IBM's Watson continues to integrate into the business world and acted as an inspiration for many forthcoming artificial intelligence systems.

\subsection{Adoption of Artificial Intelligence Globally and in China}

Organizations today, have shifted their attention to the need for AI in their business and product development and how integrating it with their business processes will change the future of their business. So, in this study, we will explore the adoption of AI by businesses and different sectors globally. Artificial Intelligence start-ups in China and investments in AI are also discussed briefly in this study.

One of the largest technological paradigm shifts is Artificial Intelligence. Just in three years the growth and importance of AI could be gauged by the fact that the number of organizations with active Artificial Intelligence projects has increased from one out of twenty-five to one out of three. Worldwide technology vendors are further shifting and incorporating artificial intelligence to cloud computing, which has greatly helped the AI-based software providers to diversify their services with more facilities to the customers. Adoption to AI is still in progress, in 12 months migration to AI has tripled in number. Within the next two years, $66 \%$ of the big organizations will have AI projects implemented in their businesses.

Although AI integration and implementation in businesses have been rising all over the world, the Asia / Pacific region companies and businesses are most actively implementing it in their businesses, with Chinese businesses leading this race. Major AI development and implementation hubs are Beijing, Shanghai, Guangdong, Zhejiang, and Jiangsu. "Next Generation AI Development Plan" was released by China in 2017 which is a three-step plan to make China and Chinese firms a leader in AI implementation. The plan is set as follows: develop Chinese competitiveness in AI by 2020; bringing AI breakthroughs by 2025; strengthening global AI management by 2030 (MMC Ventures, 2019a). With the adoption of AI the organizational structure, as well as the abilities of the companies, have also changed.

Major challenges posed to the adoption of AI are developing an effective strategic policy for AI with well-defined advantages, discovering human resources with the desired skill set, overcoming challenges created due to end deployment, and leaders' lack of motivation and commitment to AI. Despite these challenges, there is a convergence to opportunities and commitment evident from high AI adoption rates in the fields of telecom, finance, healthcare, retail, and media. AI has enabled these sectors to demonstrate high-value creation capacity. Members belonging to the above sectors are regularly communicating and exploring further opportunities and methods with AI (MMC Ventures, 2019a). 


\subsection{Potential Opportunities for the Application of Artificial Intelligence}

In the last decade, AI has made great progress and it is set to shape the future. It has penetrated to all fields of life and its ever-increasing use in business decision making has made it vital tools for success for all major corporations around the world. Its use has streamlined the business processes and has considerably changed the working environments of all companies. Due to these factors, the overall cost of companies has come down leading to better financial results, which in turn improves the corporate and social profiles of companies. The use of AI has also improved the transparency in the business process especially related to financial disclosure.

Implementation of AI-based systems has enabled the companies operating in the fields of financial services to health care has enabled the organization to analyses large data in form of speech, images, videos, financial and economic data to improve business processes and decisions. These decisions are much more reliable than those taken by humans as they incorporate much larger data set and variables, these decisions also take less time than those taken by humans thus they have improved the efficiency of the companies. The predictive powers of AI-based systems can be assessed from the example that they can predict the faults which might incur in airplane engines by utilizing the available data set. Such predictive power has considerably improved the cost and efficiency of assembly lines. In the case of logistics-based companies, AI-based programs can determine weather forecasts, possible traffic routes, traffic jams in certain times of day, etc., thus cutting down on the delivery time and both direct and indirect costs associated with them. These programs are also able to improve the overall customer services by and sales management as they can assess the requirements of individual customers by analyzing their data and provide personal sales packages based upon their demographics, social status, personal preferences, and gender, thus not only improving the sales revenues but also giving companies a competitive edge over its rivals. Manyika and Bughin (2018) had stated that financial intuitions are also using similar programs to assess the creditworthiness and customer financial requirements, which in turn have improved customer satisfaction and have enabled the financial products to be such as loans to disbursed with the matter of minutes. Such processes have reduced default rates and the improved overall reputation of financial institutions.

The use of AI is particularly important for developed countries that are experiencing low birth rates as they are facing human resource shortages, which have resulted in declining productivity. This issue can easily be addressed by using AI-based robotic technologies. Which can potentially fulfill the human resource and productivity gap? AI has proved its worth in the world of e-commerce as it has not only reduced cost but also improved the proficiency of complex processes (Thalassinos and Thalassinos, 2018). Such practices have improved international trade and reduced trade barriers. These practices have improved the world economic situation and increased the confidence of the general population in the present economic system 
of the world (Manyika and Bughin, 2018; Mahboud, 2017). According to Forum (2018), such activities have considerably improved the allocation of capital and overall economic growth around the world (Japparova and Rupeika-Apoga, 2017). In addition to these AI has also enabled the governments and regulators around the world to crack down on stock market manipulations, money laundering, and predictor policies adopted by large financial institutions.

One of the major hubs for utilization of AI relates to its application in labor markets, as with the advent of AI-based robotic technology the production around the world has raised sharply and cost has come down considerably. It has not only increased production but has also reduced production-related accidents and faults. This has increased demand for skilled labor as unskilled labor seems to lose its value and thus allowed production-based companies to allocate human resources to more challenging tasks such as innovation. Such activities have also enabled companies to allocate more resources to the welfare of the workers such as providing them with housing, education, and better access to health care facilities. This technology has also improved the safety environments in fields like oil exploration and mining as the development of robotics have reduced the need for human labor in these hazardous working environments, this has resulted in a reduction in work-related fatalities and saved the lives of countless human beings (Manyika and Bughin, 2018).

Although humans possess unique sets of skills that cannot be replaced by any machine, but the main advantage of computers related to their focus and data processing speed. One such example was the victory of IBM's Watson over candidates of "Jeopardy" due to its high speed of data processing and analysis. The main reason is simply that such machines are designed for monotone functions and as compared to humans they cannot be distracted from their tasks. According to Jaslove (2017), the main limitation human mind relates to its data processing speed which in terms hinders its analyzing ability. Meanwhile, these computers, on the other hand, have no such limitation and thus provide the organization with the analysis which is mostly error and biases free. Due to these facts, the organization has increased the usage of computers in the routine task from creating simple planner to complex tasks such as predicting the possible outcomes of financial markets. A report by MMC Ventures (2019) also endorses these ideas and highlights the potential positive impacts of such machines on the future economic environment of the world.

\subsection{Potential Threats of the Application of Artificial Intelligence in the Field of Accounting}

It is no surprise that technological advancements have molded our demands in such ways that we tend to favor technology over traditional manual means. This is particularly true for business as they would prefer to use technology as it increases their chances of growth and survival. One such example was a world-leading brand 
in "Kodak", which use to household name in photography, quickly became a relic of long forgone, when people used photographic reels. The company failed to adapt to new digital technology and did not foresee the threat posed by a digital camera and mobile phone cameras. Although they had resources but did not adapt quickly to technological changes and went bankrupt. The accounting profession may also follow their suit if they do not adapt to the environment and adapt to the new technology.

It has been long argued that advances in AI-based programming may in the future eliminate the use of humans in the field of accounting as day to day operations and their record-keeping become automated. According to one report of "Boston Consulting Group," $25 \%$ of such jobs may be replaced by automated systems by 2025 and they also suggest that the accounting profession is amongst the top $10 \%$ of jobs which companies are planning to automate (Peccarelli, 2016). Top accountancy firms such as Deloitte and KPMG have already started using AI-based applications for basic accounting tasks such as bookkeeping. This does not end here; they are also employing these systems to trace out material misstatements in financial statements with high accuracy and speed.

This eventually would phase-out the human element in the field of accounting as computers can work much faster and accurately than humans in this regard, along with the fact that they are much cheaper to operate and maintain as compared to humans. In the case of taxation practices, one of the main pillars of the accountancy profession, the consultants or accountants are required to follow the rules and regulations in both letter and spirit. This rarely happens in real-life scenarios as humans are prone to biases and personal judgments which can overshadow their professional requirements. On the other hand, this might not be a problem for the robotic program as it is not prone to such biases. When combined with the speed, accuracy, and absence of biases the computer program will prove much more effective. The absence of biases and self-interest in such programs also reduce the chances of material misstatements with the financial statements potentially making them much more useful and reliable in this field.

Jaslove (2017), states that the machine learning is mainly based upon raw data and computers can interpret the data in ways which humans cannot and thus can make predictions which are normally ignored or overlooked by a human. One of the major factors regarding the cost of using $\mathrm{AI}$ is the fact that the initial cost of implementing such systems is extremely high but in long term, this decision usually results in a lowering of overall operating cost. This also results in a lower number of employees required by accounting firms. This may lead to cost savings for an accounting firm but proves a barrier for fresh certified accountant and accounting graduates. Due to the existence of such phenomena many aspiring accountants may shift the focus of their future studies towards fields of computer sciences or other sciences such as engineering. Another factor that may contribute to such a decision relates to a flurry of accounting scandals at the start of the twenty-first century such as Enron, 
WorldCom, Tyco, etc., involving the world's largest accounting firm Arthur Anderson (AA).

The companies involved in the above-mentioned scandals used SPV's to get rid of their toxic assets present in their balance sheets by repackaging them into new instruments. These companies were aided in this fraudulent activity by the accounting professionals of AA. Since they acted as auditors and consultants at the same time, they conveniently ignored these instruments and did not mention them in their audit reports. Thus, providing a false audit report on the financial position of these companies (Investopedia, 2016). Such scandals not only resulted in the demise of AA but also proved to the vulnerability of the accounting profession. As on their inceptions, the bankruptcy of Enron and WorldCom were the largest bankruptcies in the corporate history, the US government intervened and passed the "Sarbanes Oxley Act" in 2002 commonly known as SOX act. This act allowed the US government to implement a tight regimen of rules and regulations on the public accounting firms. One of the main points of SOX was its focus on internal controls and their effectiveness within the organization. This act also required the auditors along with the management of companies to issue a certificate stating that financial statements audited by the accountants and issued by management provide a true and fair view of the company's financial situation.

Thus, implying that they do not contain any material misstatements. Such scandals are indicative of human judgment and their venerability. It has been long argued that human judgment is mostly subjective as they can easily fall prey to greed and selfinterest. Whenever there is a large sum of money involved the people acting as supervisory roles such as auditors can collude with management and falsify the reports and can maneuver the processes in such a way that these collisions go unnoticed for long periods. Such arguments provide weight to the use of AI-based programs to conduct crucial functions such as accounting and auditing. AI-based programs can easily be developed which follow the U.S. GAAP fully and thus eliminate such collusions and malpractices in the accounting profession.

\subsection{Improvement of the Application of Artificial Intelligence in the Field of Chinese Accounting Industry}

With the advent of globalization, the world is said to be shrinking and countries come closer to each other the competition in the corporate sector has also increased. To be competitive, China needs to adopt the latest accounting practices and in this regards the government of China needs not only to introduce reforms in this sector, but the accountancy professionals also need to adopt various technological developments in the field include the use of AI. The government can achieve this by giving the rebates in taxes for initial capital expenses incurred by companies in implementing the systems. 
Secondly, the leading information technology-based companies such as Microsoft, Google, and Apple have invested large sums of money in AI-based markets and are on the verge of creating a monopoly in the AI market. The Chinese internet leader "BAT" is also following their suit and has started to invest considerable resources in AI-based technologies and other companies like Alibaba have already developed AIbased technologies to facilitate their existing business model and services. These include AI-based customer support robot, which can answer different customer queries and facial recondition in for financial transactions and services provided by Alibaba. The introduction of such technologies and services has greatly improved the prestige and financial performance of Alibaba. Many businesses have shifted their focus towards the development and implementation of AI-based technologies.

By processing the "Big Data" using high-speed computers the companies can analyze the potential for their products and services promptly to avoid future losses and setbacks. Such application in fields like accounting always increases the cost in the short run but companies can exploit their benefits in the long run as the overall operating costs tend to come down considerably (Polyakova et al., 2019).

Thirdly, the educational higher education institution and vocational training institution should decide, to offer such courses to students so that they may better be able to adapt to these changes. At the same time, they should also develop the capacity of existing human resources so that this objective can be achieved.

They also need to incorporate such changes in their curriculum. These institutions also need to prepare students especially in the field of accounting to be flexible so that they can easily adapt to their working environment when they step into practical life. This can only be achieved when students not only have sound knowledge of the application of accounting processes and procedures but also have a particularly good theoretical background. The instructors of such courses need to have sound knowledge of international accounting and financial reporting standards, and consistently need to update their knowledge and skill level (Luo, Meng, and Cai, 2018).

Fourth, the practicing accountants need to place more emphasis on developing their professional skills and following the ethical standards set by the accountancy bodies around the world. As per proposals of "13th Five-Year Plan for Accounting Reform and Development" the professional bodies not only need to promote the implementation of financial and management accounting principles but also need to groom the young talented students and practitioners in this field as far China is concerned (Ministry of Finance, People Republic of China. 2016). The main reason for this relates to the fact that the Chinese accountancy profession is in a transition stage. They are following the suite of developed nations when it comes to the use of $\mathrm{AI}$ in the accounting field. 


\section{Conclusion}

The main objective of the present study was to explore and investigate the impact created by the use of AI techniques in the accounting industry. The impact of AIbased applications, the challenges relating to it, and its potential impact on future opportunities was identified and explored.

Lately, Chinese economic development has reached its panicle, and to achieve further growth and maintain competitive and comparative advantages, the companies need to adopt the latest AI-based technologies. This also holds for the accounting industry as being already in the transition phase it is required by market forces to not only adopt the latest practices but also adopt the latest technologies. In this regard, the Chinese government is aware of these requirements and is doing its best to facilitate the companies and industries in this respect. This can only be achieved if all the major stakeholders are on one page such as companies, accountants, educational institutions, and government, which seems to be happening in China at the moment.

\section{The Future of Artificial Intelligence}

One factor that cannot be ignored in the current and future scenario is the use of information technology in all fields of life including the business environment. Nowadays one cannot imagine doing business without the aid of these technologies. Some people might argue that many job sectors such as accountancy will be taken over by AI-based codes and robots, but nothing can be farther than truth. But the day to day tasks will change dramatically and the people who possess skill set related to the use of IT tools and techniques in the field of accountancy are much more likely to survive and prosper as compared to old school number crunchers. In the future, the focus will shift to analysis rather than just entering the financial data.

Although computers are better able to conduct analysis, this analysis is useless without human interpretation and human creativity and imagination cannot be replaced by AI-based programs or robots. No matter how secure the IT-based systems become there is always deep fear amongst the markets that in case of any disruption in this system the whole economic system might collapse. So, to address such fears, experts have advised against relying solely on such systems for all decisions. We predict that soon the accounting curriculums will also include subjects related to programming and the use of AI for accounting routine functions. These changes will not only ensure the survival of accounting professionals but also increase their productivity and enhance their skill sets.

\section{References:}

Best, J. 2017. IBM Watson. TechRepublic. TechRepublic, n.d. Web. 27 Mar.

Deloitte. 2017. Deloitte Forms Alliance with Kira Systems to Drive the Adoption of 
Artificial Intelligence in the Workplace. PR Newswire. Cision Company, 8, Mar.

Dilek, S., Çakır, H., Aydın, M. 2015. Applications of artificial intelligence techniques to combating cyber crimes: A review. arXiv preprint arXiv:1502.03552.

Forum, W.E. 2018. The future of jobs reports 2018.

Greenman, C. 2017. Exploring the impact of artificial intelligence on the accounting profession. Journal of Research in Business, Economics, and Management, 8(3), 1451.

Griffin, O. 2016. How artificial intelligence will impact accounting. Economia.

Investopedia. 2017. Enron Scandal: The Fall of a Wall Street Darling. Investopedia. 2 Dec.

Japparova, I., Rupeika-Apoga, R. 2017. Banking Business Models of the Digital Future: The Case of Latvia. European Research Studies Journal, 20(3A), 846-860.

Jaslove, C. 2017. The rise of artificial intelligence: An analysis of the future of accountancy.

KPMG Invests in Game-changing Cognitive Technologies for Professional Services. 2017. KPMG, 28 June.

Luo, J., Meng, Q., Cai, Y. 2018. Analysis of the Impact of Artificial Intelligence application on the Development of Accounting Industry. Open Journal of Business and Management, 6(4), 850-856.

Mahboud, R. 2017. Main Determinants of Financial Reporting Quality in the Lebanese Banking Sector. European Research Studies Journal, 20(4B), 706-726.

Manyika, J., Bughin, J. 2018. The promise and challenge of the age of artificial intelligence. McKinsey Global Institute Executive Briefing.

Ministry of Finance of the People's Republic of China. 2016. Notice on Printing and Distributing the Outline of the 13th Five-Year Plan for Accounting Reform and Development. Central People's Government of the People's Republic of China. http://kjs.mof.gov.cn/zhengwuxinxi/zhengcefabu/201610/t20161018_2437976.html

Peccarelli, B. 2016. The Robo-Accountants Are Coming. CFO. com, May, 9.

Polyakova, A.G., Loginov, M.P., Serebrennikova, A.I., Thalassinos, E.I. 2019. Design of a socio-economic process monitoring system based on network analysis and big data. International Journal of Economics and Business Administration, 7(1), 130-139.

Thalassinos, I.E., Thalassinos, E.Y. 2018. Financial Crises and e-Commerce: How Are They Related? Available at SSRN: https://ssrn.com/abstract=3330169.

Yudkowsky, E. 2008. Artificial intelligence as a positive and negative factor in global risk. Global catastrophic risks, 1(303), 184. 